\title{
Corrigendum: Model tests of energy piles with and without a vertical load
}

\section{Cheng-long Wang BEng, PhD}

Research student, College of Civil Engineering, Chongqing University, Chongqing, China

\section{Han-long Liu BEng, PhD}

Professor, College of Civil Engineering, Chongqing University, Chongqing, China

\section{Gang-qiang Kong BEng, PhD}

Professor, College of Civil and Transportation Engineering, Hoha University, Nanjing, Jiangsu, China

\section{Charles W. W. Ng MSC, PhD}

Chair Professor, Civil Engineering Department, Hong Kong University of Science and Technology, Hong Kong, China

Di Wu BEng

Graduate student, College of Civil Engineering, Chongqing University, Chongqing, China
The authors regret that the following errors were made in this paper when it was published in Environmental Geotechnics 3(4): 203-213.

The sentence 'After cooling, TS1, T3 and T6 recorded the minimum temperatures of $8.5,12.88$ and $13.63^{\circ} \mathrm{C}$, respectively, under a vertical load' on page 5 should be 'After cooling, TS1, T1 and T4 recorded the minimum temperatures of $8.5,12.88$ and $13.63^{\circ} \mathrm{C}$, respectively, under a vertical load.'

The sentence 'It is possible that end restraint has less of an influence under contraction. Although tension was produced, it was far below the limit of $1450 \mathrm{kPa}$ specified in the China Design Code (GB 50010-2010)' on page 7 should be 'It is possible that end restraint has less of an influence under contraction. Although tension was produced, it was far below the limit of $1450 \mathrm{kPa}$ specified in the Code for design of concrete structures (GB 50010-2010)'. The reference 'China Academy of Building Research (2011) GB 50010-2010: Code for design of concrete structures. China Architecture and Building Press, Beijing, China (in Chinese)' should be in the reference list.

The reference citations for 'Knellwolf et al. (2012)' should have been 'Kalantidou et al. (2012). The full reference for Kalantidou et al. (2012) is 'Kalantidou A, Tang AM, Pereira JM and Hassen G (2012) Preliminary study on the mechanical behaviour of heat exchanger pile in physical model. Géotechnique 62(11): 1047-1051, http://dx.doi.org/10.1680/ geot.11.T.013

The reference Knellwolf et al. (2011) should not have been referenced. 